\title{
Disclosing the multi-faceted world of weakly interacting inorganic systems by means of NMR spectroscopy
}

\author{
Luca Rocchigiani*a ${ }^{a}$ and Alceo Macchioni* ${ }^{b}$ \\ The potentialities of NMR spectroscopy to investigate inorganic systems assembled by, or whose reactivity is affected by \\ non-covalent interactions are herein depicted. Subjects that are receiving particular attention in recent years (halogen \\ bonding and frustrated Lewis pairs) and more classical ones but still little explored (self-aggregation of ion pairs in low polar \\ solvents, behavior of MAO containing metallocenium ion pairs, and hydrogen bonding/ion pairing effects in Au(I) catalysis), \\ faced through a rather innovative approach, are considered, always focusing on the crucial information that NMR can \\ provide.
}

\section{Introduction}

Multinuclearity is a common denominator of inorganic chemistry and NMR spectroscopy and is one of the main reasons of their successful "marriage". As a matter of fact, the structure and reactivity of very many inorganic systems has been deeply and elegantly elucidated through multinuclear and multidimensional NMR, both in solution and solid state. ${ }^{1}$

In relatively more recent years, it has been shown that NMR spectroscopy might be also exploited to obtain precious information concerning the intermolecular interactions occurring in inorganic systems. ${ }^{2}$ The latter are extremely important and critically affect the establishment of supramolecular inorganic assemblies and the reactivity of coordination compounds and organometallics, often used as catalysts for reaction of industrial interest. $^{3}$

Particularly, the combination of NOE (Nuclear Overhauser Effect $)^{4}$ and diffusion NMR techniques ${ }^{5}$ emerged as an extremely powerful tool for investigating the relative orientation (NOE) and the level of aggregation (diffusion) of non-covalently bonded inorganic systems. 6

Many non-covalently bonded inorganic systems have been investigated so far and the subject has been already extensively reviewed. ${ }^{7}$ Nevertheless, new and more appealing applications have been recently discovered. Some of them are herein considered by discussing: 1) the self-aggregation of [NR $]$ X ion pairs in low polar solvents showing how the formation of ion quadruples and higher even ionic clusters is affected by the nature of the weakly coordinating $X^{-}$anion; 2 ) the aggregation properties of metallocenium ion pairs, used as catalysts for olefin polymerizations, including those containing

\footnotetext{
School of Chemistry, University of East Anglia, Norwich NR4 7TJ, United Kingdom. Email:I.rocchigiani@uea.ac.uk

Department of Chemistry, Biology and Biotechnology and CIRCC, University of Perugia, Via Elce di Sotto 8, 1-06123, Perugia, Italy.

Email: alceo.macchioni@unipg.it
}

the industrially relevant methylaluminoxane (MAO); 3) the combination of ion pairing and $\mathrm{H}$-bonding in tuning the reactivity of gold(I) cationic catalysts; 4) non-covalent interactions in halogen-bonded adducts; 5) the supramolecular structure of intermolecular Frustrated Lewis Pairs.

\section{Results and Discussion}

\section{Self-aggregation of $\left[\mathrm{NR}_{4}\right][\mathrm{X}]$ salts}

The organisation of ionic systems into larger supramolecular assemblies in solution is still a rather poorly understood phenomenon, directly correlated to the intimate structure of the elemental aggregating unit, which is the ion pair. Understanding the behaviour of ionic systems in solution is a basic task that, nevertheless, might also shed some light on the properties of ionic functional materials and performances of catalysts of practical importance.

NMR is (one of) the technique of choice for rationalizing the structure of ionic assemblies in solution. In order to show the potential of $\mathrm{NMR}$, let us consider quaternary ammonium salts $[\mathrm{N}(\mathrm{CH})(\mathrm{CH})][\mathrm{X}]$, featuring different anions $\left[\mathrm{X}^{-}=\mathrm{BF}^{-}, \mathrm{PF}^{-}\right.$,

$$
\begin{array}{lllll}
3 & 2 & 18 & 37 & 2
\end{array}
$$
$\mathrm{OTf}^{-}, \mathrm{NTf}_{2}{ }^{-}, \mathrm{BPh}_{4}{ }^{-}, \mathrm{BTol}_{4}{ }^{-}, \mathrm{B}\left(3,5-\left(\mathrm{CF}_{3}\right)_{2}-\mathrm{C}_{6} \mathrm{H}_{3}\right)_{4}{ }^{-}\left(\mathrm{BAr}^{\mathrm{F}}\right),{ }^{4} \mathrm{~B}\left(\mathrm{C}_{6} \mathrm{~F}_{5}\right)_{4}{ }^{-}$

]$^{8}$ and see how NMR can be exploited to understand the effect of $\mathrm{X}^{-}$on the tendency of ion pairs to form ion quadruples and higher aggregates in low polar solvents. ${ }^{9}$

Diffusion NMR results show that ammonium salts featuring smaller counterions, such as $\mathrm{PF}_{6}{ }^{-}, \mathrm{BF}_{4}{ }^{-}$and $\mathrm{OTf}^{-}$, are mainly present as ion quadruples in benzene even at concentration values as low as $10^{-4} / 10^{-5} \mathrm{M}$. According to NOE results, small counterions approach the cation from the side of the $-\mathrm{NMe}_{2}$ moiety and give rise to a remarkably stable disposition in which two anions bridge two cations as shown in Figure 1a. The overall polarity of the ion quadruple is rather low and their further aggregation is not favourable (Figure 1 ). In the case of larger hydrogenated counterions ( $\mathrm{BPh}_{4}{ }^{-}$and $\mathrm{BTol}_{4}{ }^{-}$), the tendency to form ion quadruples is notably reduced (Figure 
1b). This was ascribed to the steric encumbrance of the anions that destabilizes the geometry of the quadruple. On the other hand, the resultant dipole moment of ion quadruples is much higher and the tendency to form higher aggregates is dramatically enhanced (Figure 1b). For example, $\left[\mathrm{N}\left(\mathrm{CH}_{3}\right)_{2}\left(\mathrm{C}_{18} \mathrm{H}_{37}\right)_{2}\right]\left[\mathrm{BPh}_{4}\right]$ forms nano-aggregates larger than 150 $\mathrm{nm}^{3}$ at around $60 \mathrm{mM}$ concentration. Larger fluorinated anions $\left(\mathrm{BAr}^{\mathrm{F}-}\right.$ and $\left.\mathrm{B}\left(\mathrm{C}_{6} \mathrm{~F}_{5}\right)_{4}{ }^{-}\right)$show a low tendency to form ion quadruples as well, but their tendency to self-aggregate into larger clusters is notably reduced with respect to their hydrogenated counterparts. It is reasonable to assume that the different polarisation of the fluorinated anions compensates partially the positive charge of the cation and lead to a decreased overall dipolar moment.

a)

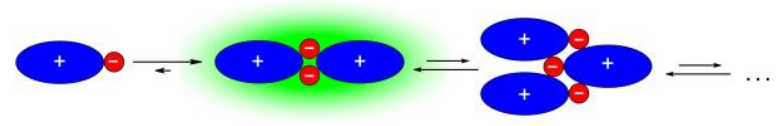

b)

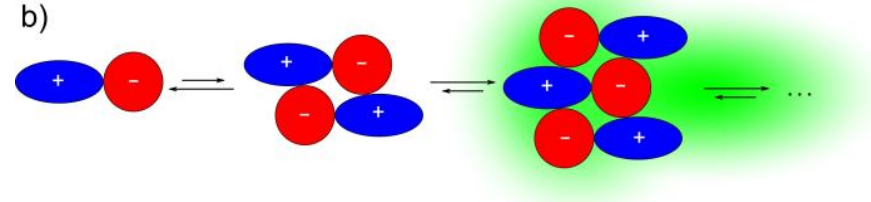

Figure 1. Sketch of the self aggregation tendency of $\left[\mathrm{NMe}_{2}\left(\mathrm{C}_{18} \mathrm{H}_{37}\right)_{2}\right][\mathrm{X}]$ salts in low polar solvents.a) Counterions smaller than the cation favour the formation of ion formation of higher aggregates.

By analysing diffusion data with the help of the indefinite aggregation models, ${ }^{10}$ two quantitative scales of the anion

effect on the tendency of $\left[\mathrm{N}\left(\mathrm{CH}_{3}\right)_{2}\left(\mathrm{C}_{18} \mathrm{H}_{37}\right)_{2}\right][\mathrm{X}]$ salts to give ion quadruples (IQ) and larger ionic clusters (IC) are obtained:

IQ: $\mathrm{BF}_{4}{ }^{-} \approx \mathrm{PF}_{6}{ }^{-} \approx \mathrm{OTf}^{-}>\mathrm{NTf}_{2}{ }^{-}>\mathrm{B}\left(\mathrm{C}_{6} \mathrm{~F}_{5}\right)_{4}{ }^{-} \geq \mathrm{BPh}_{4}{ }^{-} \geq \mathrm{BTol}_{4}{ }^{-} \geq \mathrm{BAr}^{\mathrm{F}-} \mathrm{IC}:$ $\mathrm{BTol}_{4}{ }^{-}>\mathrm{BPh}_{4}{ }^{-}>\mathrm{NTf}_{2}{ }^{-}>\mathrm{B}\left(\mathrm{C}_{6} \mathrm{~F}_{5}\right)_{4}{ }^{-}>\mathrm{BAr}^{\mathrm{F}-}>\mathrm{BF}_{4}{ }^{-} \approx \mathrm{PF}_{6}{ }^{-} \approx \mathrm{OTf}^{-}$

\section{Metallocenium ion pairs featuring methylaluminoxane (MAO)}

As mentioned above, ion-pairing can dramatically affect the activity of organometallic catalysts. Perhaps, metallocenium catalysts for homogeneous olefin polymerisation are the class of compounds where ion-pairing effects are most evident. ${ }^{11,12}$ Because olefin polymerizations are carried out in solvents with very low relative permittivity, using extremely electrophilic and unsaturated catalysts, substrate and counterion, indeed, compete for the coordination at the metal centre; as a consequence, it is possible to switch from inactive to extraordinarily efficient catalysts by slightly reducing the coordinating ability of the anion. ${ }^{12}$ Among the number of suitable counterions, mainly based on perfluorinated borates, those derived from the exploitation of methylaluminoxane (MAO) as co-catalyst have a prominent position since they are extensively used in industrial processes.

Diffusion NMR shows that the hydrodynamic behaviour of MAO is dependent on the type and concentration of MAO itself. ${ }^{13}$ For example, when commercial solutions containing $\mathrm{MAO}$ and $\mathrm{AlMe}_{3}$ are treated to reduce the content of the latter, thus obtaining depleted MAO (DMAO), the dimensions in solutions increased by $35 \%$. Furthermore, the volume of DMAO is about $25 \%$ larger when the total concentration increases by one order of magnitude. When bulky phenols such as 2,6ditertbutylphenol (TBP) are used to scavenge residual $\mathrm{AlMe}_{3}$ from DMAO, the hydrodynamic properties of the alumoxane change again. MAO cages were indeed found to increase in dimensions owing to a structural rearrangement and inclusion of O-Aryl moieties into the cages. $^{13}$

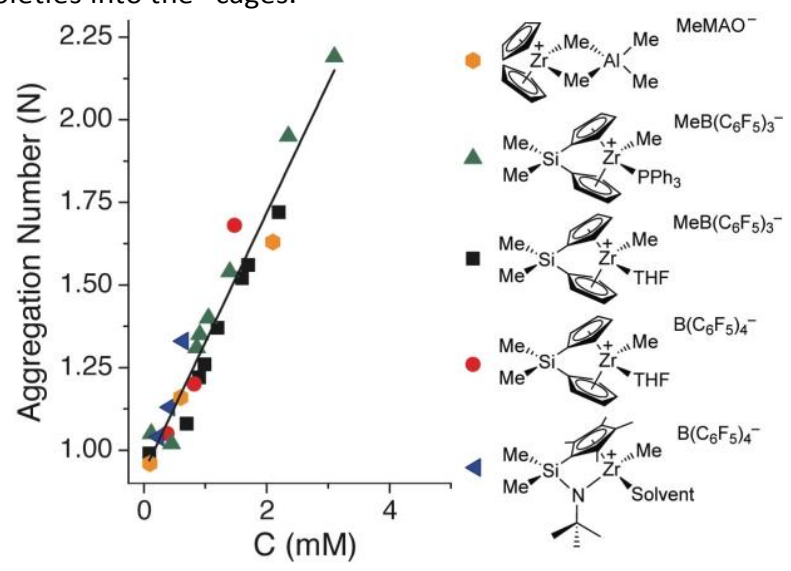

Figure 2. Aggregation number $(\mathrm{N})$ versus $\mathrm{C}$ trend for several metallocenium OSIPs in benzene or toluene. Reproduced from ref. 9.

The reaction of DMAO with $\mathrm{Cp}_{2} \mathrm{ZrMe}_{2}$ at $\mathrm{Al} / \mathrm{Zr}$ ratios around 50 leads to the formation of the inner sphere ion pair (ISIP) $\left[\mathrm{Cp}_{2} \mathrm{ZrMe} \cdots \mathrm{MeMAO}\right.$, featuring a $\mathrm{MeMAO}^{-}$closely interacting with the metal, and the bimetallic outer sphere ion pair (OSIP)

$\left[\mathrm{Cp}_{2} \mathrm{Zr}\left(\mu-\mathrm{Me}_{2}\right) \mathrm{AlMe}_{2}\right][\mathrm{MeMAO}]$, in which MeMAO is displaced into the second coordination sphere by the interaction of $\mathrm{AlMe}_{3}$ with the zirconium metal center. Diffusion NMR data as a function of the concentration reveal that the self- aggregation tendency of the ISIP is identical to that of DMAO, while that of the OSIP is much higher, likely due to its higher dipole moment. ${ }^{13}$ It is worth noticing that when the effect of MAO aggregation was subtracted, the self-aggregation trend of $\left[C p_{2} Z r(\mu-\right.$ $\left.\left.\mathrm{Me}_{2}\right) \mathrm{AlMe}_{2}\right][\mathrm{MeMAO}]$ nicely tracks with those of similar metallocenium outer sphere ion pairs featuring borate anions and different ancillary ligands (Figure 2). Basically, this indicated that the dipolar moment of ion pairs featuring the $\mathrm{MeMAO}^{-}$anion in the second coordination sphere is very similar to those featuring $\mathrm{MeB}\left(\mathrm{C}_{6} \mathrm{~F}_{5}\right)_{3}{ }^{-}$or $\mathrm{B}\left(\mathrm{C}_{6} \mathrm{~F}_{5}\right)_{4}{ }^{-}$anions. Such a piece of information, derived by diffusion NMR, can be crucial for understanding the behaviour of MAO-based ion pairs in solution.

\section{$\mathrm{Au}(\mathrm{l})$ catalysed dearomatisation of indoles}

Ion pairing is known to affect the reactivity of all transition metal complexes. ${ }^{3}$ Quite recently, anion/cation interactions were found to play a key role also in the activation of unsaturated substrates towards nucleophilic attack catalysed by $\mathrm{Au}(\mathrm{I})$ cationic complexes ${ }^{14,15}$ and NMR has been exploited to disclose such a role. $^{16} \mathrm{~A}$ notable example is the 
dearomatization of indoles with allenamides catalysed by $\mathrm{L}-\mathrm{Au}-$ $X$ salts $\left(L=\left\{2,4-\left({ }^{t} B u\right)_{2}-C_{6} \mathrm{H}_{3} \mathrm{O}\right\}_{3} \mathrm{P}, \quad X=\right.$ counterion), because ion pairing/coordination and hydrogen bonding synergistically contribute in determining the outcome of the reaction. In particular, the reaction of 2,3-dimethyl- $1 \mathrm{H}$-indole with $\mathrm{N}$ - phenyl$\mathrm{N}$-tosyl-allen-1-amine occurs through the nucleophilic attack by the $\mathrm{N}$ atom of the indole when $\mathrm{X}^{-}=\mathrm{CF}_{3} \mathrm{SO}_{3}{ }^{-}\left(\mathrm{OTf}^{-}\right)$, while an unusual attack of the $\mathrm{C}(3)$ of the indole occurs when $\mathrm{X}^{-}=\mathrm{CF}_{3} \mathrm{CO}_{2}{ }^{-}$ (TFA') (Scheme 1a).
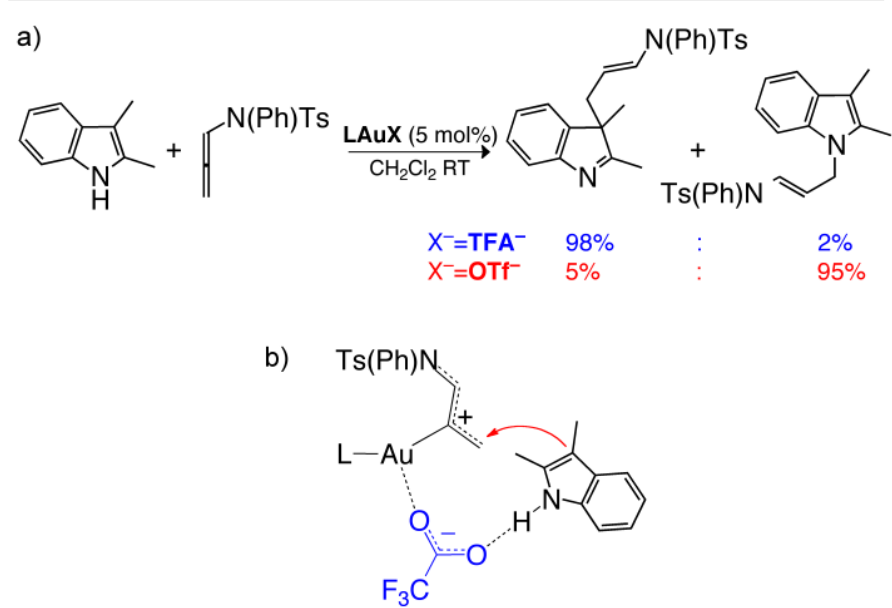

Scheme 1. a) Gold catalysed dearomative condensation of 2,3-dimethyl-indole with $\mathrm{N}$-phenyl-N-tosyl allen-1-amine. $\mathrm{L}=\left\{2,4-\left({ }^{\mathrm{B}} \mathrm{Bu}\right)-\mathrm{C} \mathrm{H} \mathrm{O}\right\} \mathrm{P}$; b) proposed

transition state for the reaction with $\mathrm{X}=\mathrm{CF}_{3} \mathrm{CO}_{2}$

$$
\begin{array}{llll}
2 & 6 & 3 & 3
\end{array}
$$

NMR results indicate a completely different behaviour of the two anions. OTf ${ }^{-}$anion is readily displaced from the first coordination sphere by both the indole and, likely, also allene, despite the interception of any complex featuring coordinated allene is not possible owing to a fast dimerization of the substrate. ${ }^{17}$ Under these conditions, it is likely that the indole attacks the electrophile through the most nucleophilic site, namely $N(1)$.

On the contrary, TFA ${ }^{-}$is so coordinating that its displacement from the first coordination sphere of gold occurs only by an excess of allene. This process possibly leads to the formation of threecoordinated species bearing both allene and TFA',

successively evolving to an OSIP, in which the anion remains in close proximity to coordinated allene. The imidazole is not basic enough and it does not replace the anion. Anyway, lowtemperature NOE studies indicate that it undergoes hydrogen bonding with coordinated TFA ${ }^{-}$(Figure 3 ). All seems to suggest that such $\mathrm{N}-\mathrm{H} \cdots \mathrm{OCOCF}_{3}{ }^{-}$hydrogen bonding interaction, likely occurring in the tricoordinated species, orients the imidazole in a way that makes less probable the nucleophilic attack of the $\mathrm{N}$ atom and favours the attack of the carbon atom at the coordinated allene, as shown in Scheme $1 \mathrm{~b}^{17}$

\section{Supramolecular structure of halogen bonded adducts}

After having showed that NMR spectroscopy may be successfully applied to characterize hydrogen bonded inorganic intermediates, let now consider systems involving halogen bonding $(X B)$.

$X B$ is attracting much attention, owing to its implication in supramolecular chemistry and crystal engineering. ${ }^{18}$
Essentially, XB originates from the interaction between a lone pair donor and polarized halogen atom, which acts as charge acceptor when is located in proximity of electron withdrawing substituents. The high directionality, arising from its peculiar nature, makes XB a powerful tool in the construction of novel supramolecular assemblies. Interestingly, the strength of interaction is quite dependent on the nature of the donor/acceptor pair to the point that the energy scale is notably large (1-40 kcal/mol). ${ }^{18-19}$ This makes XB a suitable subject for thorough experimental investigations by means of different techniques, including NMR spectroscopy. ${ }^{20}$

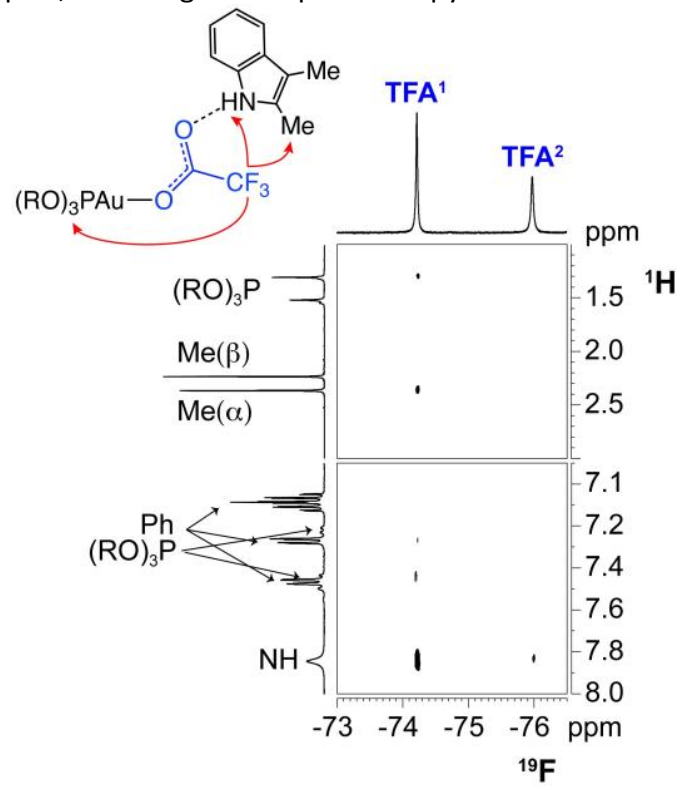

Figure $3 .{ }^{19} \mathrm{~F},{ }^{1} \mathrm{H}$ HOESY NMR spectrum of a mixture containing LAUTFA and 15 equiv of dimethyl-indole (CD Cl, $\left.233 \mathrm{~K}, \mathrm{k}=\left\{2,4-\left({ }^{(} \mathrm{Bu}\right)-\mathrm{C} \mathrm{H} \mathrm{O}\right\} \mathrm{P}\right)$. $_{2}$ The ${ }_{3}$ segond signal in the ${ }^{19} \mathrm{~F}$ spectrum is due to secondary species. Reprinted with permission from ref. 17. Copyright 2014 American Chemical Society.

Irrespective of the used technique, association constants and interaction energies of supramolecular adducts are often derived by titration methods, under the assumption that adducts are held together exclusively by XB. This is not necessarily true and other intermolecular forces, like lone pair$\pi$ ones, ${ }^{21}$ may substantially contribute to the formation and stability of the adducts. ${ }^{22}$ A more direct approach based on NOE NMR may overcome this drawback as shown herein reporting the results of a recent in-depth ${ }^{19} \mathrm{~F},{ }^{1} \mathrm{H}$ NOE study carried out for combinations of prototypical XB donors and acceptors featuring interactions of different nature. ${ }^{20}$ Particularly, ${ }^{19} \mathrm{~F},{ }^{1} \mathrm{H}$ HOESY NMR spectra of toluene mixtures containing a strong acceptor such as 1,4diazabicyclo[2.2.2] octane (DABCO) and strong donors, like perfluoroiodobenzene or 1-iodo-perfluorohexane, show the presence of intense dipolar contacts between DABCO protons and the fluorine nuclei closer to the iodine atom of the donor (Figure 4a). This observation is in agreement with the formation of tight halogen bonded adducts. The lack of interactions between DABCO protons and terminal fluorine nuclei of the donors indicated a marked selectivity, leading to conclude that $\mathrm{XB}$ adducts are prevalent in solution.

Interestingly, the quantification of the NOE contacts for the DABCO/1-iodo-perfluorohexane pair indicate that the 
perfluoroalkyl chain folds in a way to orient the $\gamma-\mathrm{F}$ atom close to the $\mathrm{CH}_{2}$ of $\mathrm{DABCO}$, thus increasing the overall interaction energy (Figure 4a).

a)<smiles>FC(F)(F)C(F)(F)C(F)(F)C(F)(F)C(F)(F)C(F)(F)C(F)(F)C(F)(F)C(F)(F)C(F)(F)C(F)(F)C(F)(F)F</smiles>

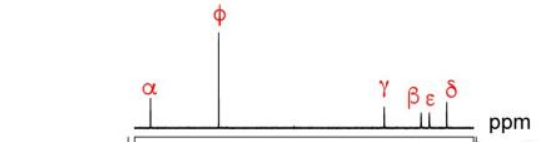

(c)

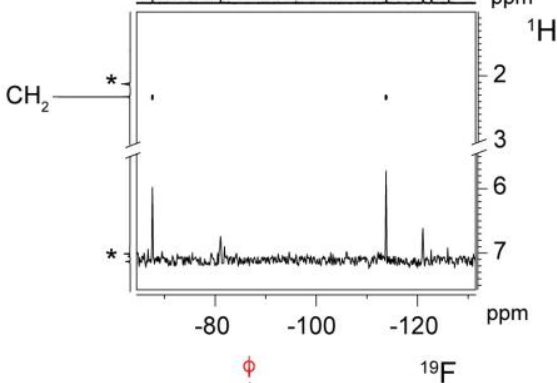

b)

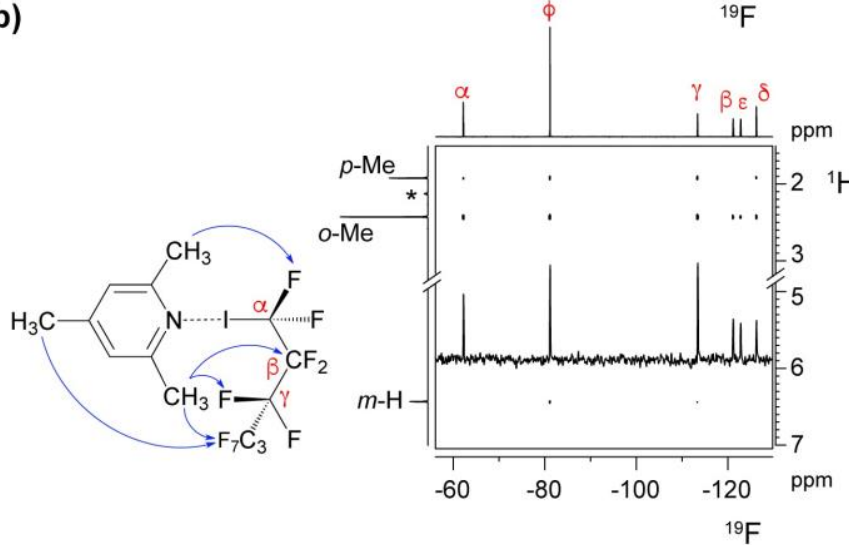

Figure 4. a) ${ }^{19} \mathrm{~F},{ }^{1} \mathrm{H}$ HOESY NMR spectrum of a mixture of DABCO $(34 \mathrm{~mm})$ and perfluoroiodohexane $(29 \mathrm{~mm})$, solvent $=$ toluene- $d_{8}$; the trace is relative to $\delta_{i a}$ $2.38 \mathrm{ppm} . \mathrm{b})^{19} \mathrm{~F},{ }^{1} \mathrm{H}$ HOESY NMR spectrum of a mixture of Me Py ( $\left.79 \mathrm{~mm}\right)$ and perfluoroiodohexane $(58 \mathrm{~mm})$, solvent $=$ toluene- $d_{8}$; the trace is relative to $\delta_{i g}=$ $2.43 \mathrm{ppm}$. Asterisks denote residual solvent peaks. Adapted from ref. 20. Copyrigh
$2015 \mathrm{~J}$ John Wiley and Sons.

Changing the nature of both donor and acceptor results in a decrease of selectivity. When DABCO is replaced by a less efficient acceptor such as 2,4,6-trimethylpyridine, the ${ }^{19} \mathrm{~F},{ }^{1} \mathrm{H}$ HOESY NMR spectrum of the mixture shows also the presence

of significant NOE interactions between donor protons and fluorine atoms far away from iodine. For example, the ortho

methyl groups of the pyridine strongly interact with the terminal $-\mathrm{CF}_{3}$ of 1-iodo-perfluorohexane, indicating that $\mathrm{XB}$ is not the only aggregation motif present in solution (Figure $4 \mathrm{~b}$ ). The same observations are obtained when DABCO is combined with a weaker acceptor such as perfluorobromobenzene, where no selectivity of interaction emerged. This suggests that other noncovalent forces, such as $\mathrm{H} \cdots \mathrm{F}$ interactions between methyl groups of 2,4,6-trimethylpyridine and $-\mathrm{CF}_{2}$ and $-\mathrm{CF}_{3}$ moieties of 1-iodo-perfluorohexane, contribute in stabilizing the supramolecular adducts.

The relative weight of $X B /$ non- $X B$ interactions may be estimated by combining quantitative NOE results with DFT calculations. ${ }^{20}$ It turns out that $\mathrm{XB}$ adducts represent more than $95 \%$ of the aggregates in solution, in the case of $\mathrm{DABCO} /$ iodoperfluoro donor combinations. On the other hand, XB adducts drop to $80 \%$ and $55 \%$ for $2,4,6$ - trimethylpyridine/1-iodoperfluorohexane and $\mathrm{DABCO} /$ per- fluorobromobenzene, respectively. Such a detailed description of $X B$ and non-XB adducts clearly demonstrated, once again, the remarkable potentialities of NOE NMR techniques, especially when complemented by DFT calculations.

\section{Intermolecular interactions in Frustrated Lewis Pairs}

The last example aimed at highlighting the successful application of NMR to disclose the structure and reactivity of weakly interacting inorganic systems deals with Frustrated Lewis Pairs (FLPs). FLPs are molecules or mixtures, principally based on main group elements, where a Lewis acid (LA) and a Lewis base (LB) coexist because their natural propensity to form dative adducts is precluded for structural reasons. They are capable of activating small molecules and can be considered as an alternative to transition metal catalysts. ${ }^{23}$ Basically, it can be thought that their acid and basic properties may synergistically act analogously to the $\sigma$-acidity and $\pi$ - basicity of a transition metal in promoting the activation of small molecules.
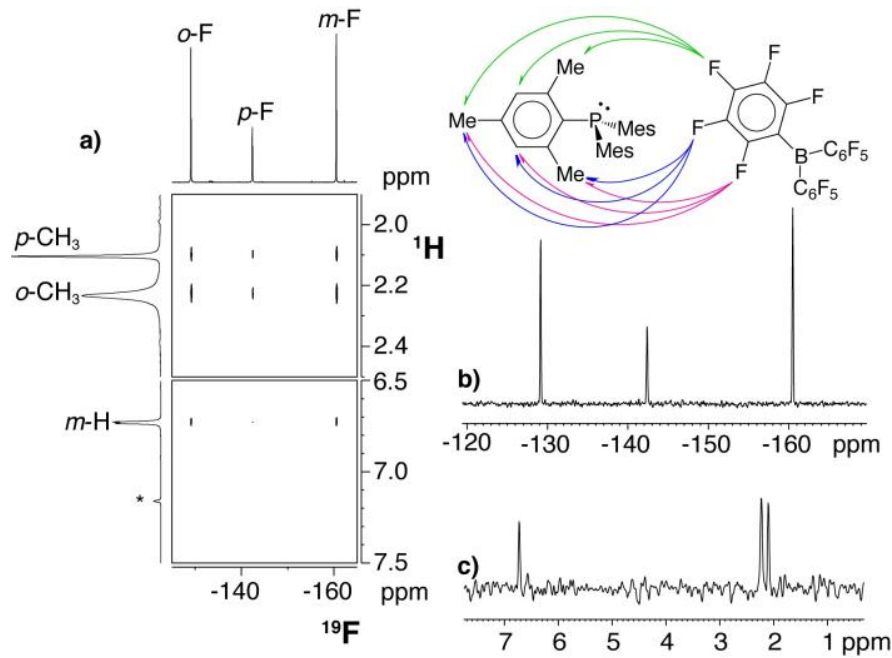

Figure 5. (a) ${ }^{19} \mathrm{~F},{ }^{1} \mathrm{H}$ HOESY NMR spectrum of $\mathrm{P}(2,4,6-\mathrm{Me} \mathrm{C} \mathrm{H} \mathrm{)} / \mathrm{B}(\mathrm{C} F) \quad(\mathrm{C}=228$

$\mathrm{mM}, \mathrm{T}=298 \mathrm{~K}$, solvent $=\mathrm{C}_{6} \mathrm{D}_{6}$, relaxation delay $=7.5 \mathrm{~s}$, mixing time $\left.=200 \mathrm{~ms}^{5}\right)^{3}$. (b) $\quad F 2$ trace at $\delta_{H}=2.1 \mathrm{ppm}$. (c) $\mathrm{F} 1$ trace at $\delta_{\mathrm{F}}=-160.5 \mathrm{ppm}$. Asterisk denotes residual solvent. Reprinted with permission from ref. 27. Copyright 2014 American Chemical Society.

One of the first and most notable examples is the heterolytic splitting of molecular hydrogen by $\mathrm{PR}_{3} / \mathrm{B}_{(}\left(\mathrm{C}_{6} \mathrm{~F}_{5}\right)_{3}$ mixtures $\left[\mathrm{R}=\mathrm{C}\left(\mathrm{CH}_{3}\right)_{3}\right.$ or $\left.2,4,6-\mathrm{Me}_{3} \mathrm{C}_{6} \mathrm{H}_{2}\right]$ to give the corresponding phosphonium borate ion pairs. ${ }^{24}$ As far as the reaction mechanism is concerned, advanced theoretical calculations suggest that hydrogen-fluorine non-covalent interactions play an important role in stabilizing a weak LA $\cdots$ LB encounter complex, in which the portion of space between donor and acceptor forms a reactive pocket where the substrate is activated. ${ }^{25}$ Anyway, an experimental validation of such mechanistic scheme is hampered by the difficulty of obtaining clear indications about the formation and structure of LA ‥LB in solution. ${ }^{26}$ Deep insights into the level of interaction between frustrated phosphines and boranes have been recently obtained by exploiting NOE and diffusion NMR techniques. ${ }^{27}$ 
Particularly, the ${ }^{19} \mathrm{~F},{ }^{1} \mathrm{H}$ HOESY NMR spectra of stoichiometric $\mathrm{PR}_{3} / \mathrm{B}\left(\mathrm{C}_{6} \mathrm{~F}_{5}\right)_{3}\left[\mathrm{R}=\mathrm{C}\left(\mathrm{CH}_{3}\right)_{3}\right.$ or $\left.2,4,6-\mathrm{Me}_{3} \mathrm{C}_{6} \mathrm{H}_{2}\right]$ mixture show the existence of weak dipolar contacts between hydrogen nuclei of the phosphine and fluorine ones of the borane (Figure 5). This suggests that a certain level of interaction between the two frustrated partners is present and could be somehow related to the formation of the elusive encounter complex. By the way, the careful quantification of the NOE contacts clearly indicates there is not any predominant LA/LB relative orientation. ${ }^{27}$ This points out that the formation of LA $\cdots$ LB is mainly driven by noncovalent $\mathrm{H} \cdots \mathrm{F}$ interactions, rather than by residual $\mathrm{P} \cdots \mathrm{B}$ bonding. As a confirmation, the same pattern of dipolar contacts were observed in the ${ }^{19} \mathrm{~F},{ }^{1} \mathrm{H}$ HOESY NMR spectrum of a $\mathrm{P}(2,4,6$ $\left.\mathrm{Me}_{3} \mathrm{C}_{6} \mathrm{H}_{2}\right)_{3} / \mathrm{C}_{6} \mathrm{~F}_{6}$ mixture in $\mathrm{C}_{6} \mathrm{D}_{6}$ where the boron LA functionality is absent. ${ }^{27}$

Even though standard titration studies are not particularly effective in detecting LA …B interactions, interesting information has been derived by variable temperature (VT) NMR spectroscopy of non-stoichiometric mixtures. As a matter of fact, in $\mathrm{P}\left(2,4,6-\mathrm{Me}_{3} \mathrm{C}_{6} \mathrm{H}_{2}\right)_{3} / \mathrm{B}\left(\mathrm{C}_{6} \mathrm{~F}_{5}\right)_{3}$ mixtures containing a 15- fold excess of phosphine, the line broadening of the ${ }^{19} \mathrm{~F} N M R$ spectrum of the borane nicely follows the dynamic behaviour of the ${ }^{1} \mathrm{H}$ NMR spectrum of the phosphine, which is due to the presence of an hindered rotation of the aromatic ring about the $\mathrm{P}-\mathrm{C}$ bond. Such a modulation of the ${ }^{19} \mathrm{~F}$ resonances strongly supports the establishment of non-covalent $\mathrm{H} \cdots \mathrm{F}$ interactions and, consequently, NOE results.

Even though NOE and VT NMR establish that frustrated

phosphines and boranes weakly interact in solution, these techniques do not provide quantitative data about the interaction energy. This information can be derived by diffusion NMR spectroscopy, through the measurement of the hydrodynamic volume values of the species in nonstoichiometric mixtures. Interestingly, even in the presence of a large molar excess of one component, the observed $V_{H}$ values of the other component only slightly deviates from that measured for the pure species. This confirms that the association in solution is remarkably weak. LA/LB association is found to be a slightly endergonic process, having $a \otimes G^{\circ}=+0.5 \mathrm{kcal} / \mathrm{mol}$, in perfect agreement with the results of previous computational studies. $^{28}$

\section{Conclusion and Outlook}

Herein an excursus over some frontier applications of NMR spectroscopy to investigate non-covalently bonded inorganic systems has been carried out. It has been shown that the exploitation of consolidated NMR techniques, such as those based on NOE and diffusion, provides unique insights into weak interactions that 1 ) are receiving enormous attention (halogen bonding and FLPs), 2) are still little explored (self- aggregation of ion pairs in low polar solvents), and 3) strongly affect the reactivity (ion quadrupoling in metallocenium ion pairs and hydrogen bonding/ion pairing in $\mathrm{Au}(\mathrm{I})$ catalysis). Everything presages that the "marriage" between inorganic chemistry and NMR spectroscopy will be long lasting for many years to come.

\section{Acknowledgements}

We thank Profs. Gianluca Ciancaleoni and Cristiano Zuccaccia for insightful discussions. LR is thankful to SABIC for support. AM thanks SABIC, UNIVATION, Fondazione Cassa di Risparmio di Perugia (2015.0338.021) and COST Action CM1205 (CARISMA).

\section{Notes and references}

1 (a) J. A. Iggo, NMR Spectroscopy in Inorganic Chemistry, Oxford, 2000; (b) K. J. D. MacKenzie, M. E. Smith, Multinuclear Solid-State NMR of Inorganic Materials, Oxford, 2002; (c) P. S. Pregosin, NMR Spectroscopy in Organometallic Chemistry, Weinheim, 2012.

2 G. Ciancaleoni, C. Zuccaccia, D. Zuccaccia, A. Macchioni in Techniques in Inorganic Chemistry (Eds. J. P. Fackler, Jr, L. R. Falvello), pag. 129-180, Boca Raton, 2010.

3 A. Macchioni, Chem. Rev., 2005, 105, 2039.

4 A. Macchioni, Eur. J. Inorg. Chem., 2003, 195.

5 (a) Y. Cohen, L. Avram, L Frish, Angew. Chem., Int. Ed., 2005, 44, 520. (b) A. Macchioni, G. Ciancaleoni, C. Zuccaccia, D. Zuccaccia, Chem. Soc. Rev., 2008, 37, 479. (c) L. Avram, Y. Cohen, Chem. Soc. Rev., 2015, 44, 586.

6 P. S. Pregosin, P. G. A. Kumar, I. Fernaǹdez, Chem. Rev., 2005, 105, 2977.

7 G. Bellachioma, G. Ciancaleoni, C. Zuccaccia, D. Zuccaccia, A. Macchioni, Coord. Chem. Rev., 2008, 252, 2224.

$8\left[\mathrm{~N}\left(\mathrm{CH}_{3}\right)_{2}\left(\mathrm{C}_{18} \mathrm{H}_{37}\right)_{2}\right]^{+}=\mathrm{N}, \mathrm{N}, \mathrm{N}, \mathrm{N}$-dioctadecyldimethyl-

ammonium; $\mathrm{OTf}^{-}=\mathrm{CF}_{3} \mathrm{SO}_{3}{ }^{-} ; \mathrm{NTf}_{2}^{-}=\mathrm{N}\left(\mathrm{SO}_{2} \mathrm{CF}_{3}\right)_{2}^{-} ; \mathrm{BTOl}_{4}^{-}=\mathrm{B}(4-$ $\left.\mathrm{CH}_{3} \mathrm{C}_{6} \mathrm{H}_{4}\right)_{4}^{-} ; \mathrm{BAr}^{\mathrm{F}-}=\mathrm{B}\left[3,5-\left(\mathrm{CF}_{3}\right)_{2}\left(\mathrm{C}_{6} \mathrm{H}_{3}\right)\right]_{4}^{-}$.

9 L. Rocchigiani, G. Bellachioma, G. Ciancaleoni, S. Crocchianti, A. Laganà, C. Zuccaccia, D. Zuccaccia, A. Macchioni, ChemPhysChem, 2010, 11, 3243.

10 R. B. Martin, Chem. Rev., 1996, 96, 3043.

11 (a) C. Zuccaccia, N. G. Stahl, A. Macchioni, M.-C. Chen, J. A. Roberts, T. J. Marks, J. Am. Chem. Soc., 2004, 126, 1448; L. Rocchigiani, C. Zuccaccia, D. Zuccaccia, A. Macchioni, Chem. Eur. J., 2008, 14, 6589; (c) L. Rocchigiani, G. Ciancaleoni, C. Zuccaccia, A. Macchioni, Angew. Chem. Int. Ed., 2011, 50, 11752.

12 (a) E. Y.-X Chen, T. J. Marks, Chem. Rev., 2000, 100, 391; (b) M. Bochmann, Organometallics, 2010, 29, 4711

13 L. Rocchigiani, A. Pastore, V. Busico, A. Macchioni, Dalton Trans. 2013, 42, 9104.

14 (a) A. S. K. Hashmi, G. J. Hutchings, Angew. Chem. Int. Ed., 2006, 45, 7896; (b) A. Fürstner, P. W. Davies, Angew. Chem. Int. Ed. 2007, 46, 3410; (c) N. D. Shapiro, F. D. Toste, Synlett, 2010, 5 , 675; (d) R. E. M. Brooner, R. A. Widenhoefer, Angew. Chem. Int. Ed., 2013, 52, 11714.

15 (a) G. L. Hamilton, E. J. Kang, M. Mba, F. D. Toste, Science, 2007, 317, 496; (b) M. Jia, M. Bandini, ACS Catal., 2015, 5, 1638.

16 (a) D. Zuccaccia, L. Belpassi, F. Tarantelli, A. Macchioni, J. Am. Chem. Soc., 2009, 131, 3170; (b) D. Zuccaccia, L. Belpassi, L. Rocchigiani, F. Tarantelli, A. Macchioni, Inorg. Chem., 2010, 49, 3080; (c) A. Zhdanko, M. Ströbele, M. E. Maier, Chem. Eur. J., 2012, 18, 14732; (d) L. Biasiolo, M. Trinchillo, P. Belanzoni, L. Belpassi, V. Busico, G. Ciancaleoni, A. D'Amora,

A. Macchioni, F. Tarantelli, D. Zuccaccia, Chem. Eur. J., 2014 20, 14594; (e) A. Zhdanko, M. E. Maier, ACS Catal., 2014, 4, 2770.

17 L. Rocchigiani, M. Jia, M. Bandini, A. Macchioni, ACS Catal., 2015, 5, 3911 
18 (a) G. R. Desiraju, P. S. Ho, L. Kloo, A. C. Legon, R. Marquardt, P. Metrangolo, P. Politzer, G. Resnati, K. Rissanen, Pure Appl. Chem., 2013, 85, 1711; (b) P. Metrangolo, H. Neukirch, T. Pilati, G. Resnati, Acc. Chem. Res., 2005, 38, 386; (c) P. Metrangolo, G. Resnati, Halogen Bonding: Fundamentals and Applications (Structure and Bonding), Springer, Heidelberg, 2010.

19 (a) P. Metrangolo, F. Meyer, T. Pilati, G. Resnati, G. Terraneo, Angew. Chem. Int. Ed., 2008, 47, 6114; (b) R. W. Troff, T. Mäkelä, F. Topic', A. Valkonen, K. Raatikainen, K. Rissanen, Eur. J. Org. Chem., 2013, 1617.

20 G. Ciancaleoni, R. Bertani, L. Rocchigiani, P. Sgarbossa, C. Zuccaccia, A. Macchioni, Chem. Eur. J., 2015, 21, 440.

21 Y. Lu, Y. Liu, H. Li, X. Zhu, H. Liu, W. Zhu, J. Phys. Chem. A, 2012, 116, 2591.

22 N. Ma, Y. Zhang, B. Ji, A. Tian, W. Wang, ChemPhysChem, 2012, 13, 1411.

23 (a) D. W. Stephan, G. Erker, Angew. Chem. Int. Ed., 2015, 54, 6400; (b) D. W. Stephan, Acc. Chem. Res., 2015, 48, 306; (c) D. W. Stephan, J. Am. Chem. Soc., 2015, 137, 10018.

24 G. C. Welch, D. W. Stephan, J. Am. Chem. Soc., 2007, 129, 1880.

25 (a) T. A. Rokob, A. Hamza, A. Stirling, T. Soós, I. Pápai, Angew. Chem. Int. Ed., 2008, 47, 2435; (b) T. A. Rokob, I. Bakó, A. Stirling, A. Hamza, I. Pápai, J. Am. Chem. Soc., 2013, 135, 4425.

26 L. Rocchigiani, Isr. J. Chem., 2015, 55, 134.

27 L. Rocchigiani, G. Ciancaleoni, C. Zuccaccia, A. Macchioni, J. Am. Chem. Soc., 2014, 136, 112.

28 A. Stirling, A. Hamza, T. A. Rokob, I. Pàpai, Chem. Commun., $2008,3148$.

\section{FOR GRAPHICAL ABSTRACT:}

The potentialities of NMR spectroscopy to investigate inorganic systems whose structure and reactivity is affected by non-covalent interactions are herein described; supramolecular assemblies based on relatively unusual intermolecular forces or on more classical ones, still rather unexplored in solution, are considered.

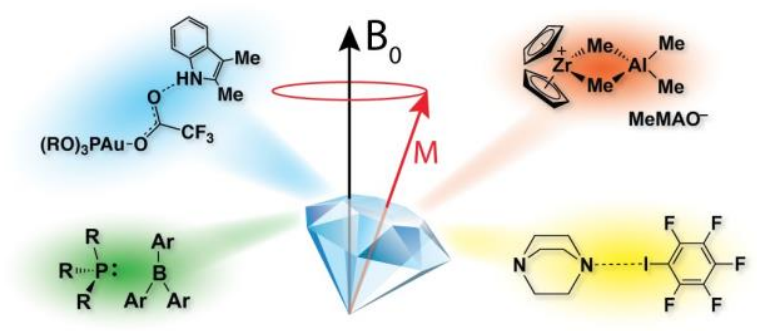

